Article

\title{
Temperature- and Time-Dependent Mechanical Behavior of Post-Treated IN625 Alloy Processed by Laser Powder Bed Fusion
}

\author{
Alena Kreitcberg ${ }^{1}$, Karine Inaekyan ${ }^{1}$, Sylvain Turenne ${ }^{2}$ and Vladimir Brailovski ${ }^{1, *}$ \\ 1 Department of Mechanical Engineering, École de Technologie Supérieure, 1100 Notre-Dame Street West, \\ Montreal, QC H3C 1K3, Canada \\ 2 Department of Mechanical Engineering, École Polytechnique de Montréal, 2900 boul. Édouard-Montpetit, \\ Montreal, QC H3T 1J4, Canada \\ * Correspondence: vladimir.brailovski@etsmtl.ca; Tel.: +1-(514)-396-8594; Fax: +1-(514)-396-8530
}

Received: 21 June 2019; Accepted: 26 August 2019; Published: 29 August 2019

\begin{abstract}
The microstructure and mechanical properties of IN625 alloy processed by laser powder bed fusion (LPBF) and then subjected to stress relief annealing, high temperature solution treatment, and hot isostatic pressing were studied. Tensile testing to failure was carried out in the $25-871{ }^{\circ} \mathrm{C}$ temperature range. Creep testing was conducted at $760{ }^{\circ} \mathrm{C}$ under $0.5-0.9$ yield stress conditions. The results of the present study provided valuable insights into the static and creep properties of LPBF IN625 alloy, as compared to a wrought annealed alloy of similar composition. It was shown that at temperatures below $538^{\circ} \mathrm{C}$, the mechanical resistance and elongation to failure of the LPBF alloy were similar to those of its wrought counterpart, whereas at higher temperatures, the elongation to failure of the LPBF alloy became significantly lower than that of the wrought alloy. The solution-treated LPBF alloy exhibited significantly improved creep properties at $760^{\circ} \mathrm{C}$ as compared to the wrought annealed alloy, especially under intermediate and low levels of stress.
\end{abstract}

Keywords: nickel-based superalloys; additive manufacturing; high temperature mechanical properties; creep resistance

\section{Introduction}

Nickel-based Inconel 625 alloy has numerous applications in the aeronautics, aerospace, marine, chemical, and petrochemical industries [1,2]. The alloy is generally used in a medium temperature range $\left(250-593^{\circ} \mathrm{C}\right)$ for structural applications requiring high strength and excellent corrosion resistance, and in a high temperature range (over $593{ }^{\circ} \mathrm{C}$ ) for applications calling for outstanding creep resistance (ASTM E139-11, ASTM B444). These service properties can be achieved by conventional manufacturing technologies such as forging, rolling, or extrusion [3-6]; laser powder bed fusion (LPBF) additive manufacturing (AM) technology, however, offers numerous advantages over conventional manufacturing, more specifically in terms of its ability to fabricate parts with near net shapes, unique designs, added functionalities, low buy-to-fly ratios, and high productivity [7-10]. Moreover, LPBF is capable of producing fully functional parts directly from metal powder without the need for specialized tooling and intermediate processing steps.

It should nevertheless be noted that complex heat effects, which occur during LPBF and are related to highly localized multiple melting-remelting of powder and of underlying bulk materials, differ from those seen during conventional casting and welding. They are also responsible for strongly non-equilibrium heat and mass transfer and solidification phenomena leading to grain refinement, texture development, and the formation of unusual metastable phases [11-13]. High residual stresses resulting from a combination of significant temperature gradients and high cooling rates represent 
another peculiarity of LPBF; to avoid distortions and cracking, printed parts must therefore be subjected to post-processing stress relief heat treatment before they can even be removed from the build plate [14,15].

To mitigate the undesirable effects of LPBF processing on the microstructure of parts (columnar structure and precipitation formation), various post-processing heat treatments have been proposed $[12,13,16,17]$. These treatments frequently differ from those recommended for conventionally processed IN625 alloy parts, because of the previously mentioned structural features related to LPBF processing. For example, only a small amount of recrystallized structure is found in the LPBF IN625 alloy at $980^{\circ} \mathrm{C}\left(\sim 0.8 \mathrm{~T}_{\mathrm{m}}\right)$ [12], while in the conventionally deformed $(\varepsilon=0.4)$ IN625 alloy, annealing in the $900-980^{\circ} \mathrm{C}$ temperature range results in full recrystallization [18]. A fully recrystallized structure has been observed in the LPBF IN625 alloy only at temperatures higher than $1100{ }^{\circ} \mathrm{C}[12,13,16]$. Thus, numerous studies on LPBF-fabricated alloys have aimed to find an original sequence of post-processing heat treatments, which can include solution treatment, homogenization annealing, aging, etc., in order to render the service properties of LPBF parts comparable or superior to those of conventionally manufactured alloys of similar compositions.

An excellent combination of outstanding corrosion resistance and superior creep resistance, as well as the relatively high tensile strength of nickel-based IN625 alloy (up to $600{ }^{\circ} \mathrm{C}$ ), make it an interesting choice for aerospace applications. It has been shown that post-processing annealing of LPBF IN625 alloy can significantly improve its room temperature ductility as compared to its as-built state [13,19-21]. However, the assessment of mechanical properties cannot solely be limited to room temperature testing, especially for materials dedicated for service at elevated temperatures. In this context, it is known that conventionally processed nickel-based superalloys face the risk of embrittlement at temperatures higher than $600^{\circ} \mathrm{C}$, and that thermal treatments can affect this mechanical behavior either positively or negatively [22].

It has been shown, for example, that at $538{ }^{\circ} \mathrm{C}$, the mechanical resistance and the elongation to failure of an IN625 alloy that was electron beam-melted and then hot isostatically pressed (HIP, $1120^{\circ} \mathrm{C}$, $100 \mathrm{MPa}, 4 \mathrm{~h}$ ) were close to those of wrought IN625 alloy [23]. At $760^{\circ} \mathrm{C}$, however, as compared to its wrought counterpart, the laser powder-fused IN625 alloy (HIP under the same conditions as above) manifested significantly lower ductility, but similar mechanical resistance $[16,24]$. Notwithstanding the preceding, such information is very limited, which makes it difficult to compare the tensile properties of printed and wrought IN625 parts. The outstanding creep resistance of wrought IN625 alloy favors its use at elevated temperatures, but, as was the case with the tensile properties, we could not find any publicly available information on the creep properties of 3D-printed IN625 alloy.

Unlike IN625 alloy, LPBF IN718 alloy, as a precipitation-hardened alloy with a higher mechanical resistance at elevated temperatures [25], has been covered by many studies [26-30]. It was shown that LPBF IN718 alloy manifested a high build-orientation-related anisotropy of its creep properties, caused by preferentially oriented distributions of dendrites and precipitations formed during LPBF processing [26]. Furthermore, the application of the solution $\left(980{ }^{\circ} \mathrm{C}, 1 \mathrm{~h}\right)$ and aging $\left(718{ }^{\circ} \mathrm{C} / 8 \mathrm{~h}+\right.$ $621^{\circ} \mathrm{C} / 10 \mathrm{~h}$ ) heat treatments recommended by the AMS5662 specifications for forged and welded IN6718 alloy to the LPBF IN718 alloy led to lower creep rupture times, compared to the as-built state [26]. It was shown that this property degradation stems from the replacement of particle-shaped $\delta$ phase precipitates located in the interdendritic regions of the as-built alloy by needle-shaped $\delta$ phase precipitates located in the equiaxed structure of the solution-treated and aged alloy.

For the same LPBF IN718 alloy, limited data are available on its microstructure and mechanical behavior after post-processing HIP treatments. Similarly to the above-mentioned influence of the $\delta$ phase morphology, it was shown in Reference [28] that at $650{ }^{\circ} \mathrm{C}$, the HIP-treated alloy $\left(1200{ }^{\circ} \mathrm{C}\right.$, $103 \mathrm{MPa}, 4 \mathrm{~h}$ ) exhibited a lower creep rupture time compared to the as-built state. Note that this comparison was flawed, since the materials in both states were tested under the same stress of $650 \mathrm{MPa}$ ( $\sim .8$ of YS for the as-built alloy), which put the HIP material under less favorable conditions, since HIP reduces the mechanical resistance characteristics of the printed material. Nevertheless, it was assumed 
that the needle-like $\delta$ phase grain boundary precipitates found in crept HIP-treated samples could be a cause of lower creep lifetimes, but their origins were not clear; it was uncertain whether the precipitation took place during HIP or if it occurred during creep testing at $650{ }^{\circ} \mathrm{C}$. A comparison of the HIP LPBF IN718 alloy and the conventional hot-rolled IN718 alloy showed that the former manifested shorter creep lives than the latter under the same testing conditions [28].

It was also shown in Reference [27] that the application of the HIP conditions recommended for the wrought IN718 to the LPBF IN718 alloy $\left(1180{ }^{\circ} \mathrm{C}, 175 \mathrm{MPa}, 4 \mathrm{~h} \mathrm{[31])} \mathrm{triggered} \mathrm{three} \mathrm{concurrent}\right.$ phenomena, namely, microstructure homogenization, $\delta$ phase dissolution, and the formation of coarse carbide precipitates. When these phenomena were combined, they significantly improved the creep rupture time at $650{ }^{\circ} \mathrm{C}$ and $550 \mathrm{MPa}$, as compared to what was obtained in the as-built state.

Based on the above-mentioned observations, two main objectives can be established for future work: (a) Building a comprehensive database of the mechanical behaviors of LPBF IN625 alloy over a wide temperature range; for this study, the application of heat treatments recommended for the wrought alloy of the same composition was considered reasonable as a first approximation; (b) establishing a correlation between the mechanical properties of LPBF IN625 alloy and its microstructure (size of structural elements, nature and morphology of precipitates), with the ultimate goal of optimizing the post-processing conditions for this material.

This work focused on the first objective. The tensile and creep behaviors of laser powder-fused IN625 alloy subjected to stress relief (SR) annealing, solution treatment (ST), and hot isostatic pressing (HIP) were studied. The tensile behavior was studied in the 25 to $871{ }^{\circ} \mathrm{C}$ temperature range (68 to $1600{ }^{\circ} \mathrm{F}$ ), with this range corresponding to the widest service diapason recommended for IN625 alloy [32]. The creep behavior was studied at $760^{\circ} \mathrm{C}\left(1400^{\circ} \mathrm{F}\right)$ under various stresses, this temperature corresponding to the onset of the high temperature embrittlement phenomenon observed in our previous work [16]. The correlation between the mechanical behavior and the structural features will form the core of the next publication.

It should be noted that since LPBF IN625 alloy in its as-built condition is characterized by a significantly high level of residual stresses and a strongly heterogeneous microstructure, it is not suitable for practical use, and was therefore excluded from consideration in this study. Meanwhile, the microstructure and the mechanical properties of the as-built LPBF IN625 alloy at room and elevated temperatures can be found elsewhere [16,24].

Note also that in this work, the exact heat and HIP treatment conditions have been omitted and the tensile testing stress values measured normalized to protect proprietary partner information.

\section{Material and Methods}

In this study, IN625 powder (EOS GmbH, Munich, Germany) with a chemical composition corresponding to UNS N06625 and ASTM B443 was used. An EOSINT M290 (EOS GmbH, Munich Germany) laser powder bed fusion system equipped with a $400 \mathrm{~W}$ ytterbium fiber laser and the EOS IN625_Surface 1.0 Parameter Set (laser power $\sim 300 \mathrm{~W}$, scanning speed $\sim 1000 \mathrm{~mm} / \mathrm{s}$, hatching space $\sim 0.1 \mathrm{~mm}$, and layer thickness $\sim 40 \mu \mathrm{m}$ ) was employed to fabricate two types of specimens: $10 \times 10 \times$ $10 \mathrm{~mm}^{3}$ cubic specimens for microstructure evaluation, and $85 \times 18 \times 3 \mathrm{~mm}^{3}$ rectangular blanks for tensile testing (Figure 1a). The blanks were built in two directions relative to the build plate, as defined in Figure 1a, and have been referred to as vertical or horizontal (parallel or perpendicular to the build direction, respectively) throughout this paper. The chemical compositions of the IN625 powder, the as-built LPBF alloy, and the wrought annealed alloy (reference) are shown in Table 1. 
(a)

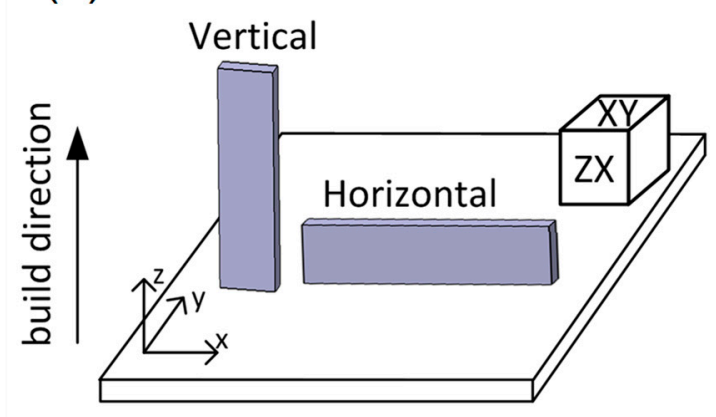

(b)

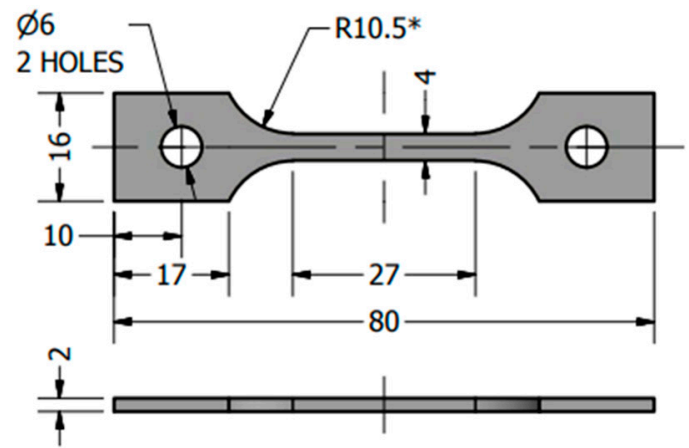

Figure 1. (a) Rectangular blanks and cubic specimens on the build plate; (b) tensile specimens (dimensions in $\mathrm{mm}{ }^{*}$ - reference dimension) [24].

Table 1. Chemical composition of IN625 alloy (in wt. \%).

\begin{tabular}{|c|c|c|c|c|c|c|c|c|c|c|c|c|c|}
\hline IN625 & $\mathrm{Ni}$ & $\mathrm{Cr}$ & Mo & $\mathrm{Nb}$ & $\mathrm{Fe}$ & $\mathrm{Ti}$ & Al & Co & C & Ta & Si & S & Mn \\
\hline $\begin{array}{c}\text { ASTM } \\
\text { B443-00 }\end{array}$ & Bal & $21.0-23.0$ & $8.0-10.0$ & $3.15-4.15$ & $\leq 5.0$ & $\leq 0.4$ & $\leq 0.4$ & $\leq 1.0$ & $\leq 0.1$ & $\leq 0.05$ & $\leq 0.5$ & $\leq 0.015$ & - \\
\hline Powder & Bal & 21.81 & 9.33 & 4.06 & 0.78 & 0.39 & 0.34 & 0.19 & 0.013 & $<0.02$ & 0.15 & 0.002 & 0.04 \\
\hline LPBF alloy & Bal & 22.42 & 9.57 & 3.95 & 1.66 & 0.07 & 0.19 & $<0.03$ & 0.012 & 0.02 & 0.17 & 0.004 & 0.04 \\
\hline $\begin{array}{l}\text { Wrought } \\
\text { alloy }\end{array}$ & Bal & 23.67 & 8.49 & 3.49 & 4.48 & 0.22 & 0.24 & 0.07 & 0.032 & 0.02 & 0.18 & 0.001 & 0.34 \\
\hline
\end{tabular}

Following the LPBF, the build plate with cubic and rectangular specimens was subjected to stress relief (SR) annealing at $\sim 900{ }^{\circ} \mathrm{C}$ for $1 \mathrm{~h}$ (EOS recommendations), followed by forced air cooling $\left(\sim 1.5^{\circ} \mathrm{C} / \mathrm{s}\right)[10,33]$. The SR treatments were carried out in a Nabertherm H41/N furnace under argon continuous flow ( $15 \mathrm{~L} / \mathrm{min})$. Next, all the printed specimens were cut from the platform, using a reciprocated saw, and the rectangular blanks were machined by EDM (electrical discharge machining) to obtain the dumbbell-shaped tensile testing specimens shown in Figure 1b.

Finally, some SR specimens were reserved for future study, while the others were subjected to either hot isostatic pressing (HIP, Avure Technologies, Quintus QIH-3, Columbus, OH, USA) under pressurized argon atmosphere, followed by furnace cooling $\left(\sim 0.1^{\circ} \mathrm{C} / \mathrm{s}\right)$ [34-36]; or high temperature solution treatment (ST) for $1 \mathrm{~h}$ in an open-air furnace (Pyradia, Longueuil, QC, Canada), followed by air cooling $\left(\sim 0.5^{\circ} \mathrm{C} / \mathrm{s}\right)$ (Figure 2$)$. Both the HIP and ST post-treatments were expected to homogenize the as-built LPBF microstructure and decrease the anisotropy of the IN625 alloy's mechanical properties. Since HIP is time- and resource-consuming, and can result in undesirable grain growth [16], ST is seen as its economic and technologically sound alternative. 


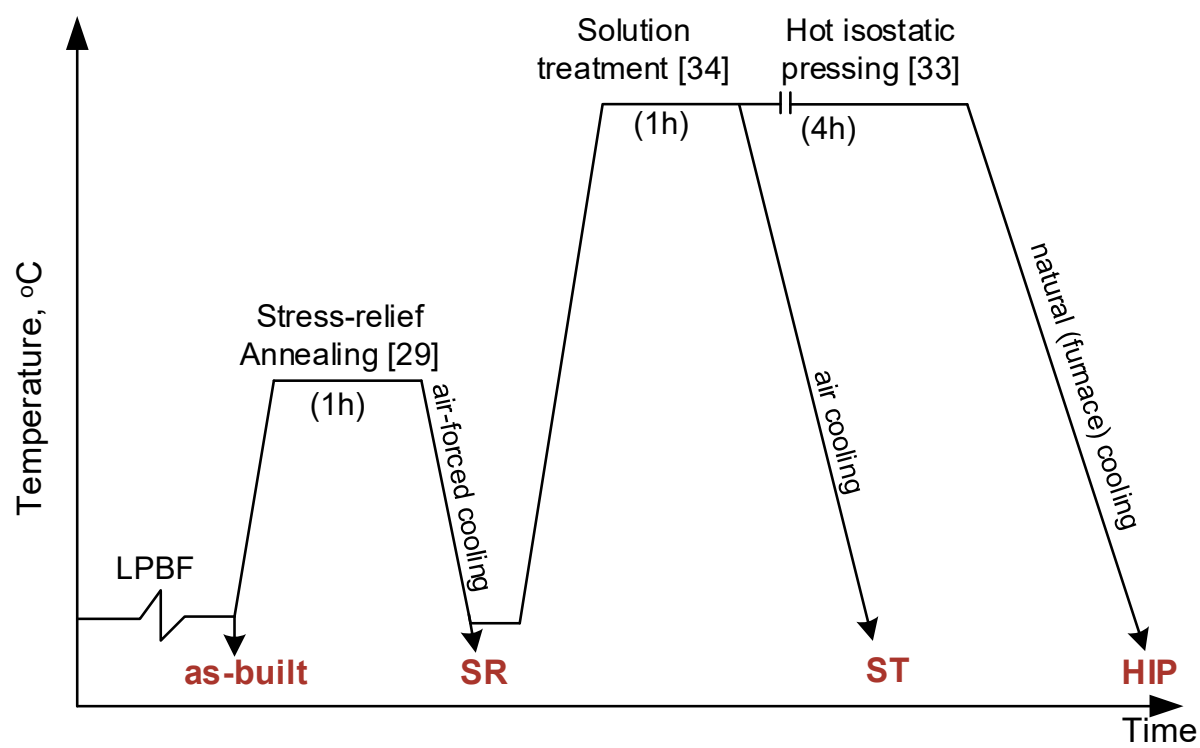

Figure 2. Schematic presentation of the post-processing sequence of laser powder bed fusion (LPBF) alloy.

For this study, it was decided to carry out both treatments at the same temperature in the $1100-1150{ }^{\circ} \mathrm{C}$ range. This decision can be explained by the fact that HIP at this temperature had already been successfully used to reduce processing-induced porosity, and to homogenize and recrystallize LPBF-built microstructures $[16,24,34]$. On the other hand, for a high carbon version of IN625 alloy $\left(\sim 0.045\right.$ wt. \%C), a typical ST temperature is also in the $1100-1150{ }^{\circ} \mathrm{C}$ range [37].

For reference, wrought IN625 alloy annealed at $980{ }^{\circ} \mathrm{C}$ (Table 1), provided by McMaster Corp. and corresponding to ASTM B443 (Grade 1, with a grain size of $\sim 13 \mu \mathrm{m}$ ), was also characterized in the framework of this study. The Grade 1 (fine-grained) alloy was chosen because it possessed higher mechanical characteristics above $600{ }^{\circ} \mathrm{C}$ than the solution-treated Grade 2 (coarse-grained) alloy. The temperature- and time-dependent behaviors of the LPBF and wrought IN625 alloys were compared in this study from the perspective of their concurrent industrial use.

Tensile testing with a strain rate of $10^{-3} \cdot \mathrm{s}^{-1}$ was conducted at $25,427,538,593,649,760$, and $871^{\circ} \mathrm{C}$ $\left(68,800,1000,1100,1200,1400\right.$, and $\left.1600^{\circ} \mathrm{F}\right)$ using an MTS 810 testing system equipped with an infrared radiant heating furnace. High temperature testing was realized under argon atmosphere at a flow rate of $5-18 \mathrm{~L} / \mathrm{h}$. Prior to tensile testing, specimens were heated at a heating rate of $1{ }^{\circ} \mathrm{C} / \mathrm{s}$ and maintained at the test temperature for $10 \mathrm{~min}$. The temperature was controlled using three K-type thermocouples in contact with the specimen surface and evenly distributed along its gauge length to control the uniformity of the temperature distribution. The strain was calculated using data provided by the LVDT (linear variable differential transducer) of the testing machine. After each treatment and for each testing temperature, the yield strength (YS corresponding to $0.2 \%$ offset strain), the ultimate tensile strength (UTS), and the elongation to failure $(\varepsilon)$ were determined. For each experimental point, three specimens were tested, and the mean values of YS, UTS, and $\varepsilon$ and their confidence ranges at a confidence probability of $p=0.95$ were calculated.

Creep tensile testing was conducted at $760{ }^{\circ} \mathrm{C}\left(1400^{\circ} \mathrm{F}\right)$ at $0.5,0.7$, and 0.9 of the YS with a loading rate of $10 \mathrm{~N} \cdot \mathrm{s}^{-1}$. The testing system, atmosphere, gas flow, and heating rates for the creep testing were identical to those of the elevated temperature tensile testing. Three tests were conducted for each creep condition, and the rupture time $(\tau)$, the fracture strain $(\varepsilon)$, and the steady or secondary creep rates $(\dot{\varepsilon})$ were determined.

The fracture morphology and microstructure were analyzed using scanning electron microscopy (SEM, Hitachi TM3030 system and Hitachi SU8230 system equipped with an electron backscatter diffraction (EBSD) unit). The microstructural analysis was performed on the horizontal (XY) and 
vertical $(Z X)$ reference faces of the cubic specimens (Figure 1a). All the specimens were polished manually (down to $1 \mu \mathrm{m}$ grit size), and then using a vibrometer and colloidal silica (0.05 $\mu \mathrm{m}$ grit size). For EBSD analysis, samples were tilted at $70^{\circ}$ and scanned at $20 \mathrm{kV}$, with a step of $1-2 \mu \mathrm{m}$.

\section{Results}

\subsection{Grain Size and Grain Orientation}

The EBSD images of the SR-, ST-, and HIP-treated specimens are shown in Figure 3. In the vertical section, the SR specimen contained grains oriented parallel to the build direction (Figure 3a). A continuous grain growth (i.e., epitaxial growth across the melt pool boundaries) during the LPBF process affected the grain orientation and the length of growing grains. In fact, the grains had an average length greater than $120 \mu \mathrm{m}$ (three layer thicknesses). Equiaxed grains with an average size of $20 \mu \mathrm{m}$ were observed in the horizontal section. After the ST and HIP treatments, the columnar grain structure of the SR alloy morphed into equiaxed grain structures (Figure 3b,c). After the ST, the grain size varied from 1 to $80 \mu \mathrm{m}$ in size, while after the HIP, it varied between 10 and $300 \mu \mathrm{m}$. Note that the average grain size $(\sim 45 \mu \mathrm{m})$ of the HIP alloy was twice as large as that of the ST alloy $(\sim 20 \mu \mathrm{m})$. The equiaxed grains with annealing twins corresponded to a low-stacking fault-free energy fcc matrix. For the SR specimens, the dominant grain texture in the build direction corresponded to the [001] direction (red area in Figure 3a), which transformed to a random texture after the ST and HIP treatments (Figure 3b,c).
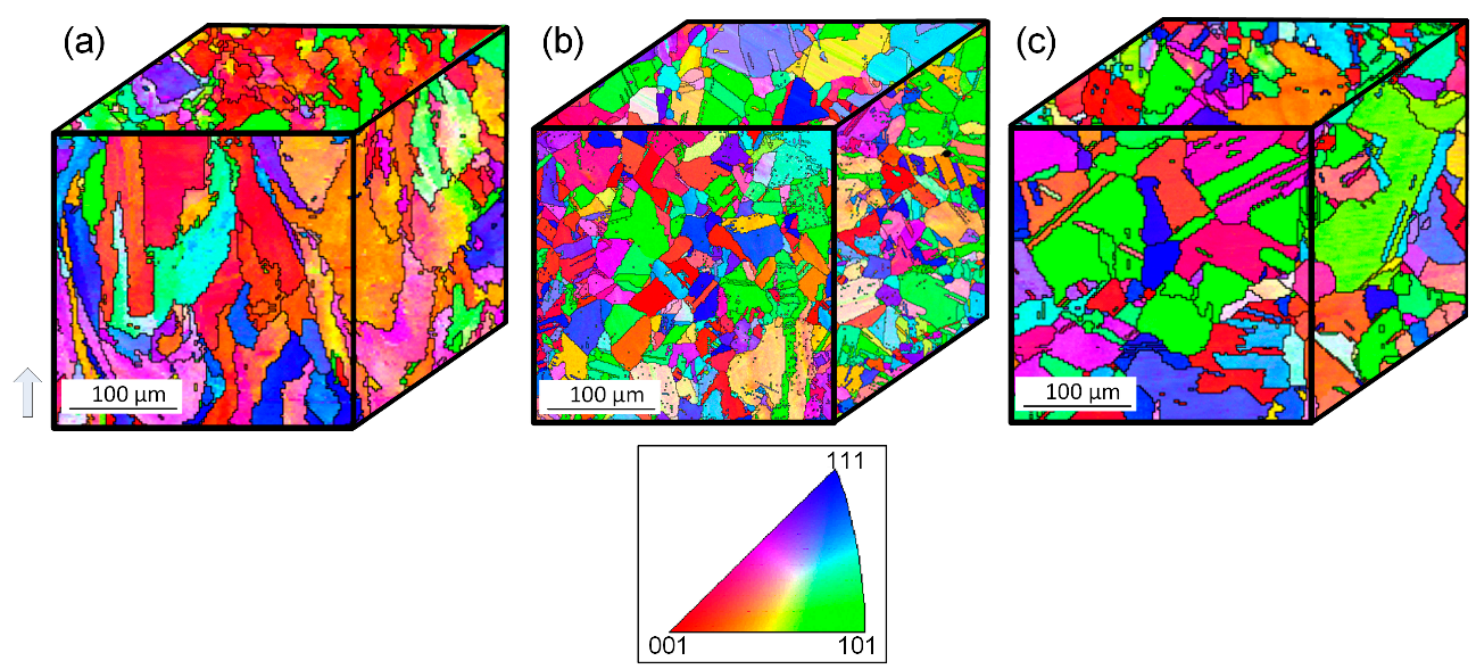

Figure 3. Electron backscatter diffraction (EBSD) images of the (a) stress-relief annealing (SR)-, (b) solution-treated (ST)-, and (c) hot isostatic pressing (HIP)-treated alloys; white arrow shows the build direction. (Color crystal orientation code is inserted.)

\subsection{Mechanical Properties at Room Temperature}

Typical RT tensile stress-strain diagrams of the SR-, ST-, and HIP-treated specimens are shown in Figure $4 \mathrm{a}-\mathrm{c}$, along with the stress-strain diagram of the wrought annealed alloy in Figure $4 \mathrm{~d}$. For the build orientation dependency evaluation, tensile diagrams for the horizontal and vertical specimens have been superimposed. 

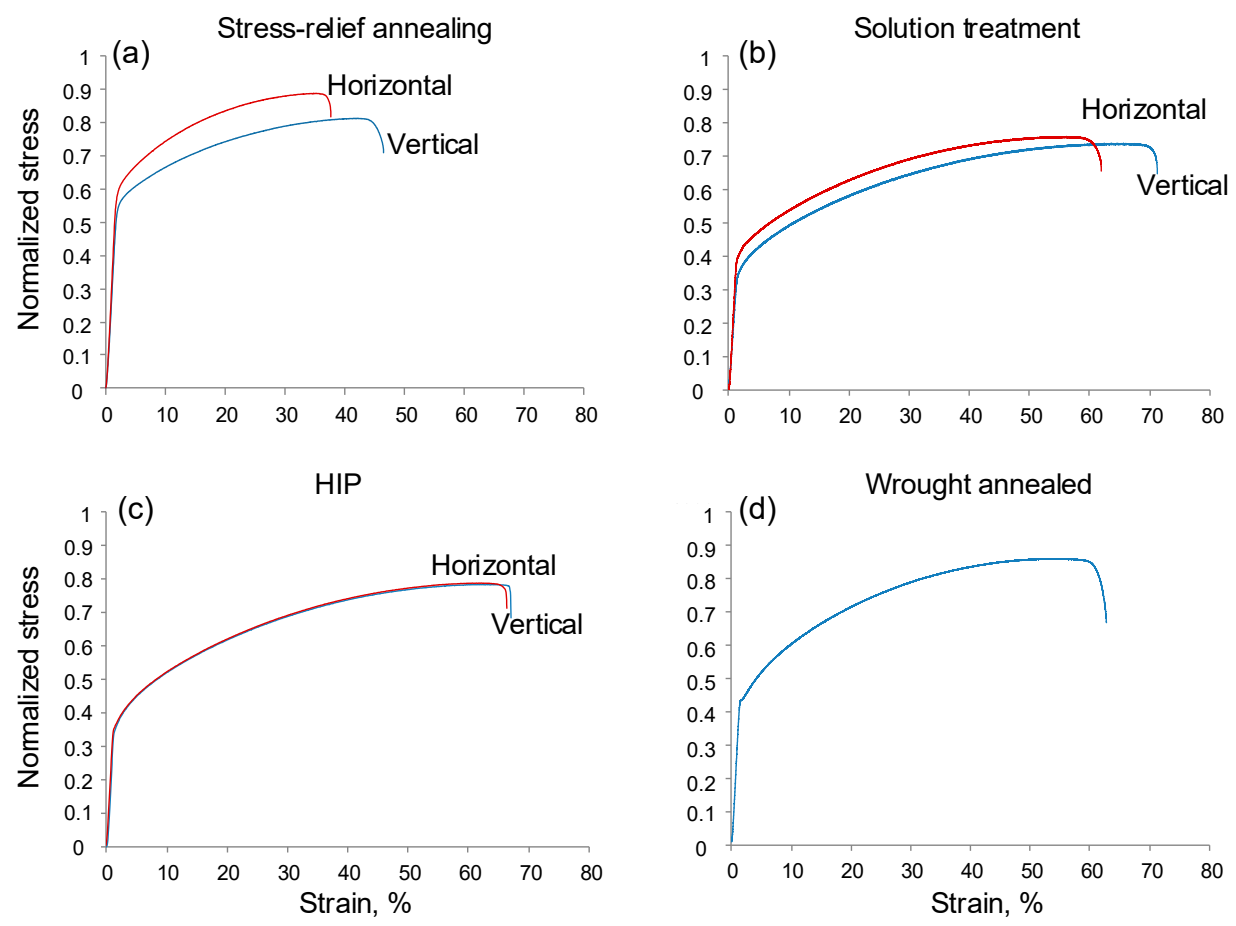

Figure 4. Tensile stress-strain diagrams (RT) of the (a) SR-, (b) ST-, and (c) HIP-treated LPBF alloy and (d) wrought annealed alloy.

An examination of these diagrams reveals that at room temperature, the SR specimens manifested the strongest build orientation dependency and the most hardened mechanical behavior as compared to their ST and HIP counterparts: after SR, the yield strength (YS) and the ultimate tensile strength (UTS) of the horizontal specimens were higher, while their elongations to failure $(\varepsilon)$ were lower than those of the vertical specimens (Figure 4a). After ST, both the strength characteristics and their orientation dependency decreased (Figure $4 \mathrm{~b}$ ), while the elongations to failure increased, as compared to the corresponding values for the SR specimens. The YS and UTS values of the horizontal ST specimens were still slightly greater than those of the vertical ST specimens, while the elongations were lower. The HIP specimens did not manifest any orientation dependency and their elongations to failure were similar to those of the ST specimens, while their strength characteristics were slightly lower (Figure 4c).

\subsection{Mechanical Properties in the $25-871^{\circ} \mathrm{C}\left(1600^{\circ} \mathrm{F}\right)$ Temperature Range}

Typical stress-strain diagrams of the SR-, ST-, and HIP-treated LPBF specimens and the wrought annealed alloy are presented in Figure 5 for the temperature ranging from 25 to $871^{\circ} \mathrm{C}\left(1600^{\circ} \mathrm{F}\right)$. 

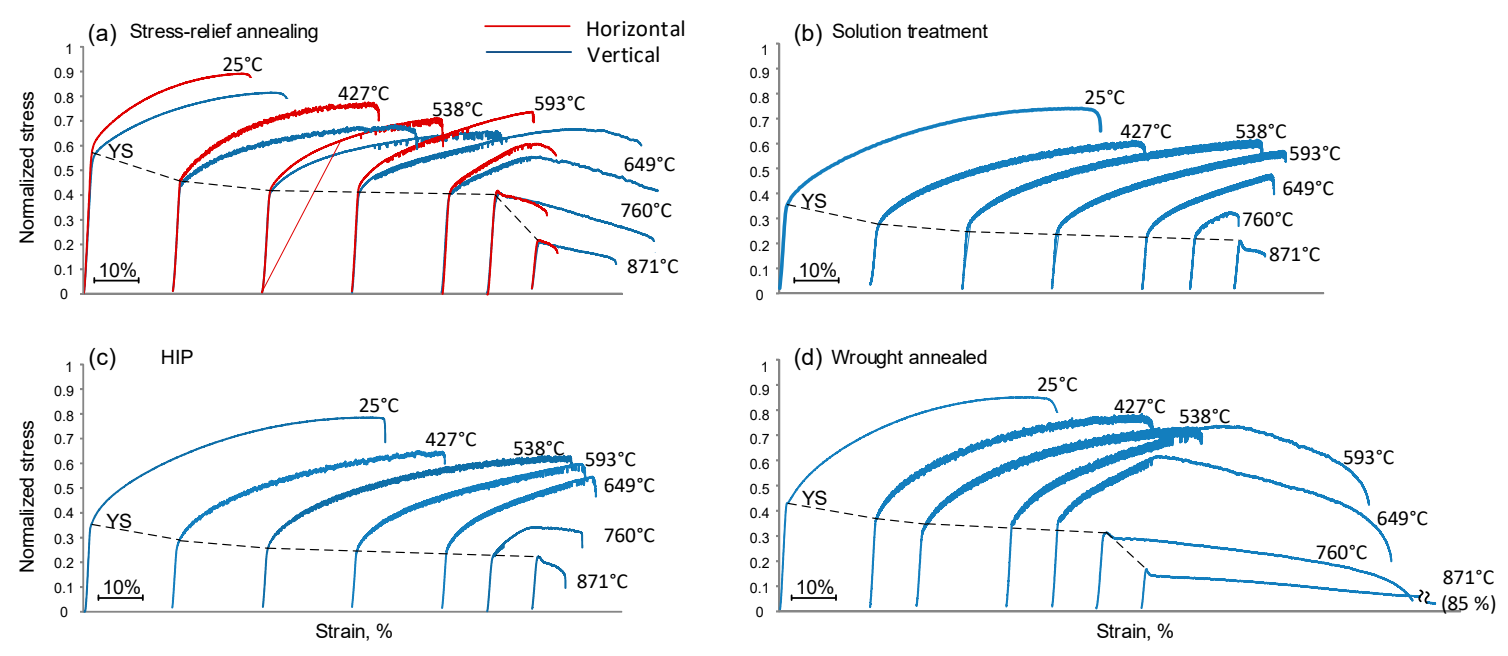

Figure 5. Stress-strain diagrams of the (a) SR-, (b) ST-, and (c) HIP-treated specimens and (d) wrought annealed alloy in the $25-871^{\circ} \mathrm{C}$ temperature range.

Globally, at elevated temperatures, the horizontal SR specimens exhibited higher YS and UTS and lower elongations as compared to their vertical counterparts (Figure 5a), which was similar to the room temperature behavior of these specimens. It was seen, however, that the higher the testing temperature, the lower the orientation dependency in terms of the YS and UTS values, but the higher this dependency in terms of their elongations to failure. As shown in Reference [16], after low temperature ST and HIP treatments, the mechanical behaviors of the corresponding specimens became build orientation-independent, and therefore, only vertical specimens were tested in the present work (Figure $5 b, c)$.

In the $427-538{ }^{\circ} \mathrm{C}$ temperature range, the SR specimens manifested the highest YS and UTS values as compared to those of the ST (HIP) and wrought alloy specimens, but at the expense of lower elongations. In this specific temperature region, the LPBF specimens (both ST and HIP) and wrought specimens manifested similar mechanical behavior. However, starting at $593^{\circ} \mathrm{C}$ and up, the ductility of the ST and HIP specimens decreased, while that of the wrought alloy increased (the same trend was observed for the SR specimens at $649^{\circ} \mathrm{C}$ and up). Vertical ST and HIP specimens manifested lower elongations than their vertical SR counterparts, but higher elongations than their horizontal SR counterparts. Thus, in the 593-649 ${ }^{\circ} \mathrm{C}$ temperature range, the mechanical behavior of the LPBF alloy was characterized by increasing brittleness, whereas the wrought alloy showed only a slight decrease in ductility.

At $760{ }^{\circ} \mathrm{C}$, both the SR and wrought specimens exhibited yield strength peaks, while the ST and HIP specimens both manifested significant work hardening. At $871{ }^{\circ} \mathrm{C}$, yield strength peaks and work softening were observed for all the specimens. At this temperature, the mechanical strength parameters of all the specimens were similar, while the elongations to failure of the LPBF alloy specimens were significantly lower than those of the wrought alloy, irrespective of the post-processing conditions of this study.

Additionally, the fracture analysis of the SR and HIP specimens after their tensile testing at 538 and $760{ }^{\circ} \mathrm{C}$ confirmed that in this temperature range, the specimens manifested fracture mechanisms corresponding to the transition from ductile to brittle behavior [24]. As seen in Figure 6, at $538^{\circ} \mathrm{C}$, the fracture surfaces showed a mostly ductile fracture mode characterized by dimples (Figure $6 \mathrm{a}, \mathrm{c}$ ), while at $760^{\circ} \mathrm{C}$, intergranular brittle fracture occurred (Figure $6 \mathrm{~b}, \mathrm{~d}$ ). Moreover, at $760^{\circ} \mathrm{C}$, after HIP, the fracture surface reflected visible triple points between equiaxed grains. 
$538^{\circ} \mathrm{C}$
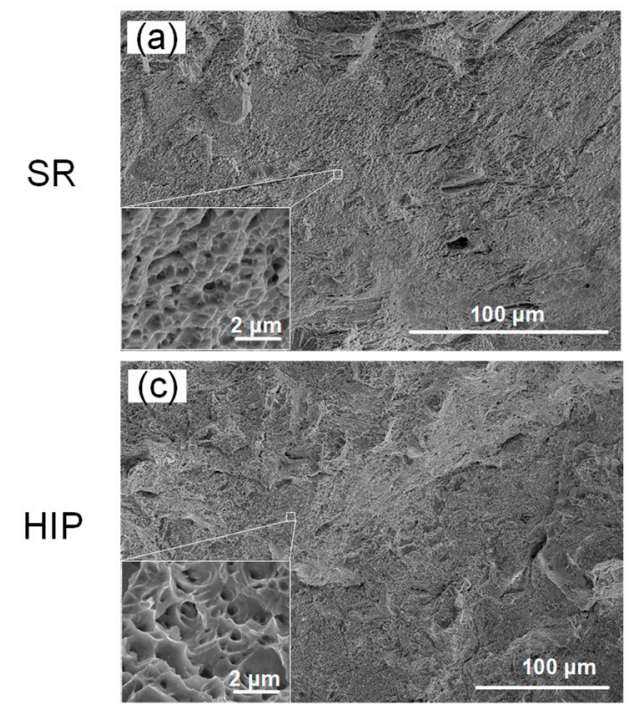

$760^{\circ} \mathrm{C}$
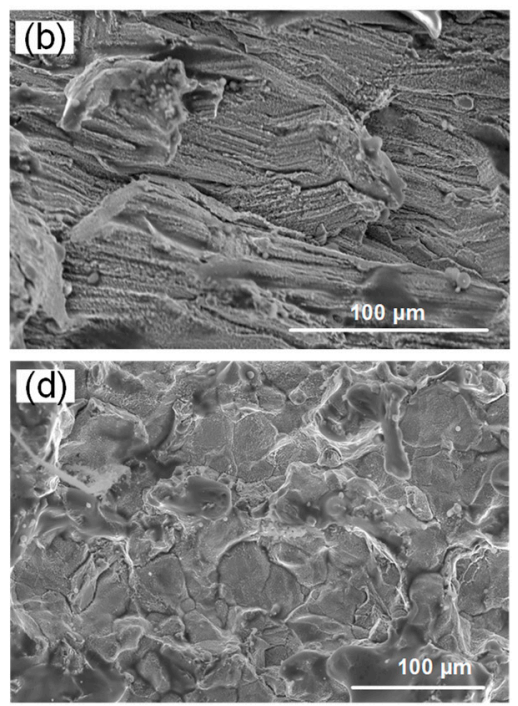

Figure 6. Fracture surfaces of the $(\mathbf{a}, \mathbf{b})$ SR (horizontal) and (c,d) HIP specimens, tensile-tested at (a,c) $538^{\circ} \mathrm{C}$ and $(\mathbf{b}, \mathbf{d}) 760^{\circ} \mathrm{C}$.

\subsection{Creep Testing}

Since the tensile mechanical properties of the ST and HIP specimens were found to be comparable across the entire temperature range of this study, only the ST-treated specimens were subjected to creep testing in accordance with ASTM E139-11 (2018), along with their SR and wrought annealed counterparts. Moreover, since the mechanical properties of the ST specimens over this temperature range were found to be build orientation-independent, only vertical ST specimens were subjected to this testing.

Figure 7 shows the typical creep diagrams for the SR, ST, and wrought annealed alloy specimens under stresses ranging from 0.5 to $0.9 \mathrm{YS}\left(760^{\circ} \mathrm{C}, 1400^{\circ} \mathrm{F}\right)$. For the LPBF specimens subjected to low ( 0.5 YS) and intermediate (0.7 YS) stresses, three stages of creep behavior were clearly distinguished: primary, secondary (steady), and tertiary (fracture), with durations dependent on the levels of stress applied. In the case of the SR specimens (Figure 7a), a secondary stage of creep was less pronounced than in the case of the ST specimens (Figure 7b), and for the SR specimens at higher stresses (0.7 YS), the transition from the primary to the steady stage was hardly distinguishable. For the wrought annealed specimens, the primary stage of creep was almost skipped (Figure 7c); the steady stage started much more quickly: the start time was $\leq 0.003 \mathrm{~h}$ as compared to the SR and ST specimens, for which this time was $0.15-0.2 \mathrm{~h}$.

(a) Stress-relief annealing

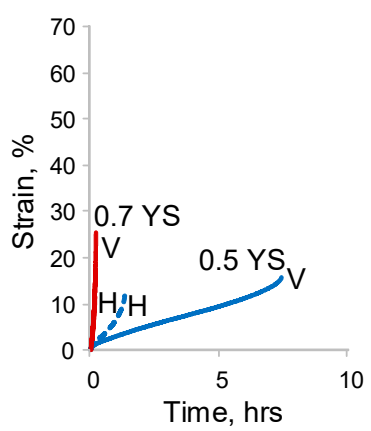

(b) Solution treatment

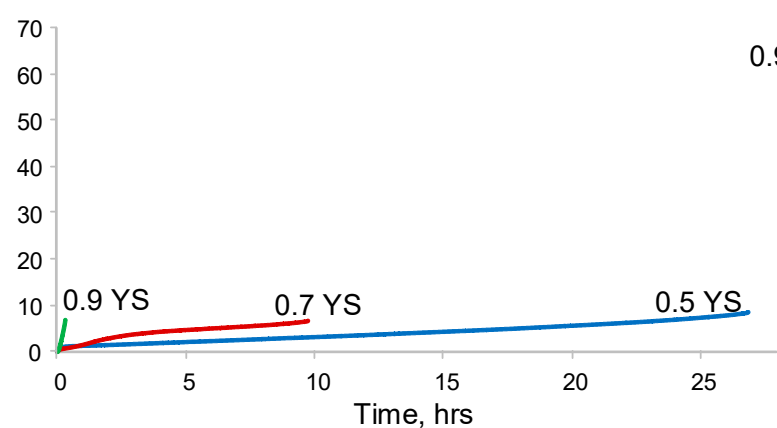

(c) Wrought annealed



Figure 7. Creep diagrams of the (a) SR, (b) ST, and (c) wrought annealed IN265 alloys at $760{ }^{\circ} \mathrm{C}$ $\left(1400{ }^{\circ} \mathrm{F}\right)$. 
Figure 8 collects the lifetime and rupture strain data for the normalized levels of creep stress ( $\sigma / Y S$ ). Note large data scattering in the case of LPBF specimens, both SR and ST, as compared to their wrought counterparts (Figure $8 \mathrm{a}$ ). In the $0.3-0.9 \mathrm{\sigma} / \mathrm{YS}$ range, the ST-treated LPBF alloy manifested a longer life to rupture (note also a run-out at $48 \mathrm{~h}$ at $\sigma / \mathrm{YS}<0.5$ ), while the $\mathrm{SR}$ and wrought specimens exhibited similar rupture times in the entire $0.3-0.9 \sigma / Y S$ range. Interestingly, the mean rupture strain in the case of the wrought specimens was significantly higher than that in the case of the SR- and ST-treated LPBF specimens (Figure 8b). The ST specimens showed the lowest mean rupture strain. Note also that the mean rupture strain values correlated well with (and did not exceed) the corresponding tensile ductility values at $760^{\circ} \mathrm{C}$ (Figure 5).

(a)



(b)

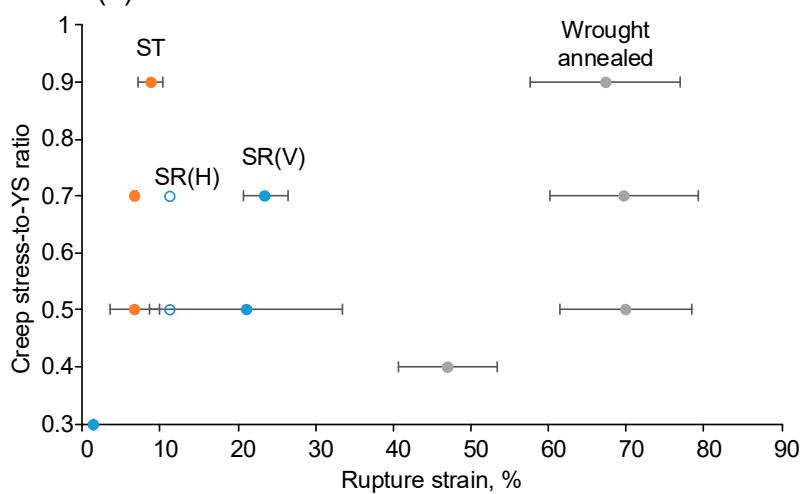

Figure 8. Applied stress in relative values ( $\sigma / Y S)$ as a function of the (a) creep rupture time and (b) rupture strain for the SR, ST, and wrought annealed IN625 alloy $\left(760^{\circ} \mathrm{C}\right)$.

After low-stress creep fracture (0.5 YS) at $760^{\circ} \mathrm{C}$, the fracture surfaces of the SR specimens had a mix of transgranular and intergranular patterns, while the ST specimens contained mostly transgranular patterns corresponding to a dimpled fracture after the same stress creep (Figure 9a,c). High stresses, however, led to mostly intergranular fractures for both the SR and ST specimens (Figure 9b,d).

The fracture surfaces of the wrought annealed alloy, containing numerous voids, dimples, and tearing ridges, indicated extremely ductile behavior of this alloy as compared to that of the ST-treated LPBF alloy, under creep conditions at $760^{\circ} \mathrm{C}$ (Figure 9e,f).

Finally, it is worth mentioning that the SR specimens exhibited a build orientation dependency of creep properties. The vertical specimens showed a more pronounced steady stage (Figure 7a) and a higher lifetime and rupture strain (Figure 8) as compared to their horizontal counterparts. Note also that the horizontal SR specimens demonstrated significantly lower tensile and creep properties than their vertical counterparts (Figures 5 and 7). 

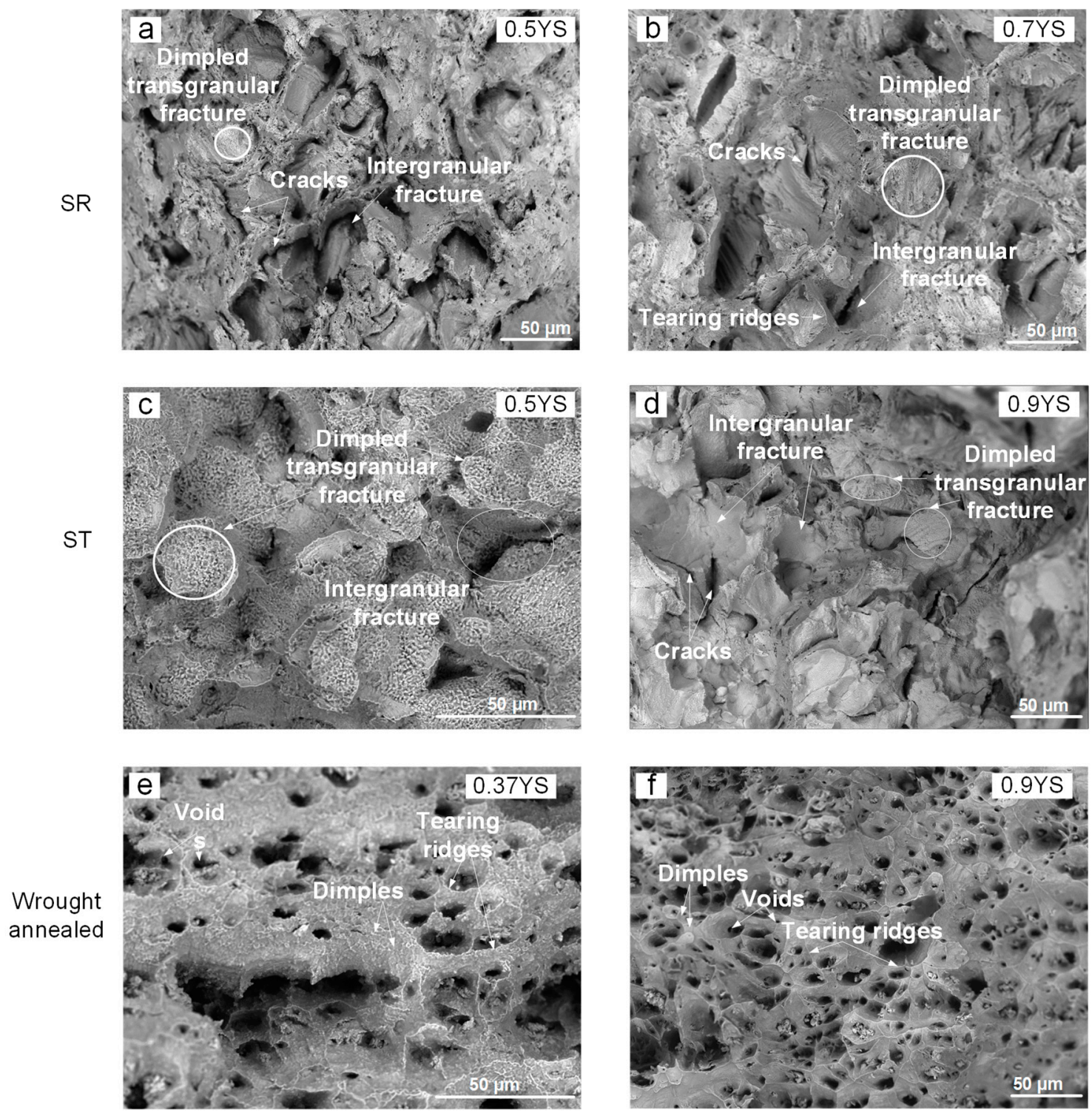

Figure 9. Scanning electron microscope (SEM) images of the fracture zones of creep specimens: $(\mathbf{a}, \mathbf{b})$ SR, (c,d) ST, and (e,f) wrought annealed IN625 alloys.

\section{Discussion}

Grain size and grain orientation. It was shown that LPBF processing was responsible for the formation of an anisotropic microstructure. The SR specimens contained grains elongated in the build direction with the dominant [001] texture, inherited from the as-built material. The grain length was more than twice the layer thickness, while the average width was about $20 \mu \mathrm{m}$. During the ST and HIP treatments, grain growth caused the microstructure to become nearly equiaxed with a random texture. The average grain sizes after the ST and HIP treatments were about 20 and $45 \mu \mathrm{m}$, respectively [16].

Map of the mechanical properties. The mechanical properties obtained at a $10^{-3} \cdot \mathrm{s}^{-1}$ strain rate across a wide range of temperatures are shown in Figure 10a-c for the SR-, ST-, and HIP-treated LPBF IN625 alloys, respectively. The mechanical properties of the vertical and horizontal SR specimens have been presented here, while the properties of the ST and HIP specimens are limited to those of the vertical specimens. For reference, the mechanical properties of the wrought annealed alloy are also illustrated in Figure 10d. 

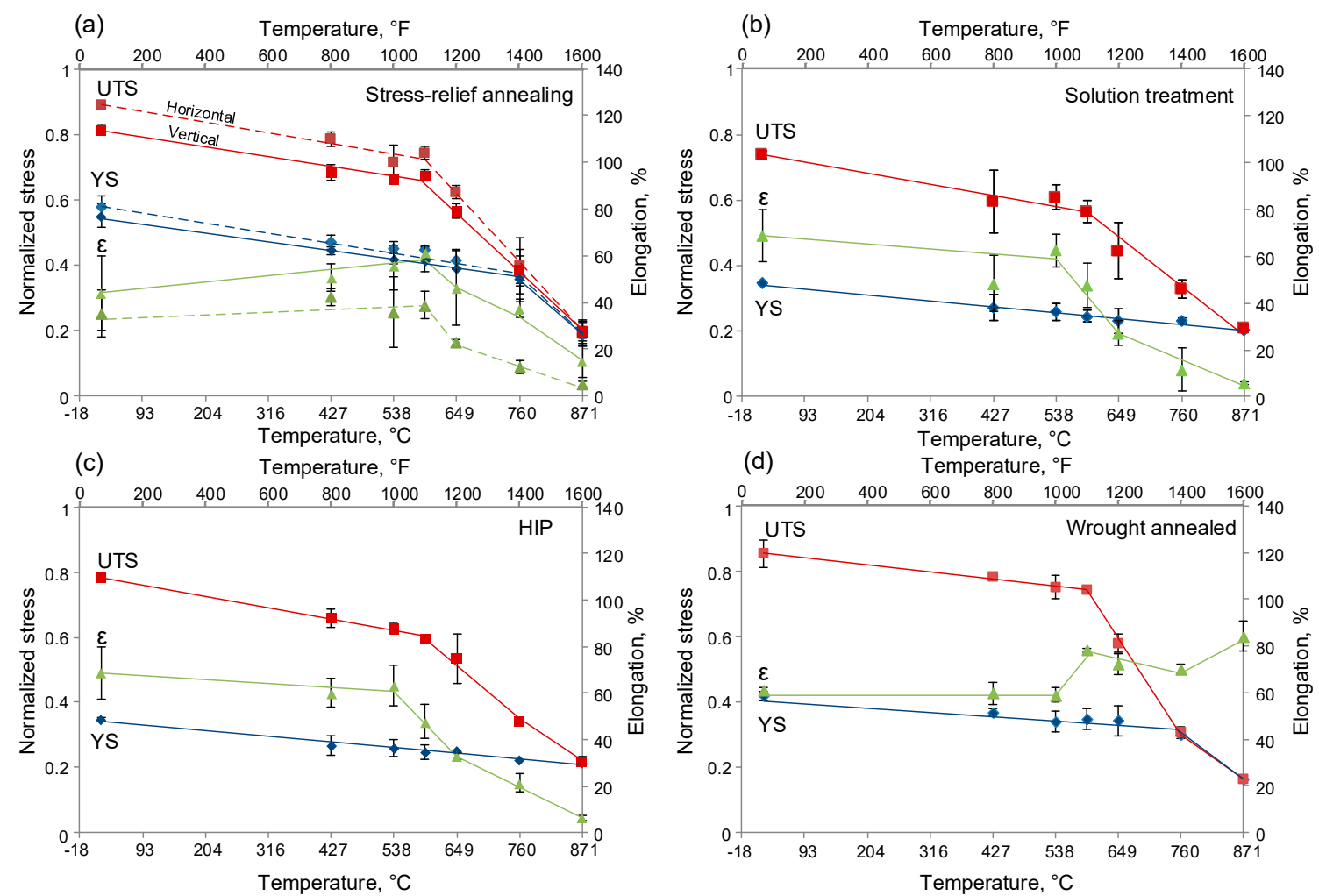

Figure 10. Mechanical properties of the (a) SR, (b) ST, (c) HIP, and (d) wrought annealed IN625 alloys as a function of temperature.

Regarding the mechanical properties overall, all specimens exhibited a decrease in the YS and UTS values as the test temperature increased, due to enhanced plastic flow causing tensile deformation at relatively lower stresses (Figure 5). However, their elongations to failure evolved differently, as discussed further.

Tensile strength characteristics (YS, UTS): The results show that at room temperature, the SR specimens exhibited the highest mechanical strengths (YS and UTS) (Figure 10a) and their mechanical strength characteristics exceeded those reported in the ASTM F3056-14 standard (min. $275 \mathrm{MPa}$ (YS) and min. $485 \mathrm{MPa}$ (UTS)) and EOS datasheet (min. $414 \mathrm{MPa}$ (YS) and min. $827 \mathrm{MPa}$ (UTS)) for LPBF IN625 alloy. Regarding other studies, the mechanical properties at room temperature of the SR specimens obtained in this study were comparable to those reported in References $[13,19,21,38]$ for the as-built LPBF IN625 alloy. However, the high mechanical strength of the SR specimens came with a significant orientation dependency in the mechanical characteristics due to a strong microstructure anisotropy, which was inherited from the as-built material [16]. Thus, a finer microstructure in the build plane resulted in higher YS and UTS values of the horizontal specimens as compared to their vertical counterparts. By contrast, the ST and HIP specimens containing equiaxed grains and a random texture manifested build-orientation-independent behavior, but lower mechanical strength characteristics. The equiaxed grain structure and reduced mechanical strength characteristics after post-treatments performed at temperatures higher than $1100^{\circ} \mathrm{C}$ have also been reported in References [13,21].

At elevated temperatures of up to $593^{\circ} \mathrm{C}$, the YS and UTS values decreased continuously with increasing temperature for all the tested specimens. The orientation dependency and the high mechanical strength characteristics of the SR specimens were preserved at these temperatures. The YS and UTS values of the ST and HIP specimens were still slightly lower than those of the wrought annealed alloy.

With a further temperature increase to up to $760^{\circ} \mathrm{C}$, a rapid decrease in mechanical strength characteristics was observed for the SR specimens, which was caused by dynamic recrystallization [24]. 
As a result, no difference was observed between the YS and UTS values. The ST- and HIP-treated specimens were capable of maintaining their structural strength to up to $760^{\circ} \mathrm{C}$, and their UTS values became comparable to those of the SR specimens. For the ST- and HIP-treated specimens, dynamic recrystallization took place at $871{ }^{\circ} \mathrm{C}$. At this temperature, the YS and UTS values of all the tested specimens were comparable.

Elongation to failure: From RT to intermediate temperatures $\left(538^{\circ} \mathrm{C}\right)$, the elongations to failure increased for all the specimens. However, the peak in elongations was observed at $593^{\circ} \mathrm{C}$ for the SR specimens, and at $538{ }^{\circ} \mathrm{C}$ for the ST and HIP specimens. Note that for the wrought annealed alloy, the elongation always increased with an increase in testing temperature (Figure 10d). At higher temperatures, the LPBF alloy manifested a significant reduction in elongation. Such a significant decrease in elongation of the LPBF alloy at $760^{\circ} \mathrm{C}$ was accompanied by changes in fracture pattern due to weakening of the grain boundaries at elevated temperatures (ductile/brittle transition) [24]. Moreover, the intergranular cracking mode led to a significant increase in the orientation dependency for the SR specimens in the $593-871^{\circ} \mathrm{C}$ temperature range. The elongated grains oriented along the axis of testing were responsible for higher elongations of the vertical SR specimens as compared to their horizontal counterparts. After the ST and HIP treatments, the grains became equiaxed and their mean size increased, resulting in elongations to failure higher than for the horizontal SR, but lower than for the vertical SR specimens.

The elevated temperature embrittlement observed in this study is a known phenomenon for many Ni-based alloys. The reasons for this behavior are subject to discussion [22]. In particular, the embrittlement has been attributed to intergranular precipitates, grain boundary shearing or sliding, gas phase embrittlement, dynamic strain aging, grain boundary segregation, and glide plane decohesion [22]. For IN625 alloy, this phenomenon is mostly associated with precipitates (carbides, $\mathrm{M}_{23} \mathrm{C}_{6}$ and $\mathrm{M}_{6} \mathrm{C}$, and $\delta$ phase) distributed along grain boundaries [2,24,39,40]. More specifically, according to Reference [24], cracks preferentially propagate along grain boundaries containing $\mathrm{M}_{6} \mathrm{C}$ carbides.

Finally, it should be mentioned that the mechanical behaviors of the ST- and HIP-treated specimens were similar (Figure 10b,c). While the YS and UTS values of the ST specimens were slightly higher, their elongations were slightly lower than those of the HIP specimens.

High-temperature creep properties. It was found that as well as the tensile properties, the SR-annealed alloy exhibited orientation dependency of its creep behavior: vertically built specimens showed higher lifetimes and lower rupture strains compared to their horizontally built counterparts (Figures 7 and 8). Despite the high lifetimes of the vertical SR specimens as compared to the vertical ST and wrought specimens (Figure 11), the anisotropy in mechanical properties of the SR LPBF IN625 alloy makes its behavior unpredictable. Thus, heat treatment including only stress-relief annealing is not recommended for the practical use of LPBF IN625 alloy.

Regarding the ST-treated LPBF alloy, at the same creep-to-yield stress ratio, the ST specimens exhibited significantly improved creep properties as compared to the reference wrought annealed alloy. However, in the "absolute creep stress-rupture time" diagram (Figure 11), at first sight, the ST specimens still had an advantage over the wrought annealed alloy, especially at intermediate and low stresses ( $\leq 200 \mathrm{MPa})$. Using the "strain-time" creep curves, the steady creep rates were measured and are collected in Figure 12. It was clearly observed that the higher the applied stress, the higher the steady creep rate, which led to shorter lifetimes for the SR, ST, and wrought alloys, and a higher fraction of the intergranular fracture areas for the SR and ST alloys. However, it was seen that under the same creep stress of $\geq 150 \mathrm{MPa}$, the steady creep rates for the wrought and SR-treated LPBF alloys were higher than that for the ST-treated LPBF alloy. 


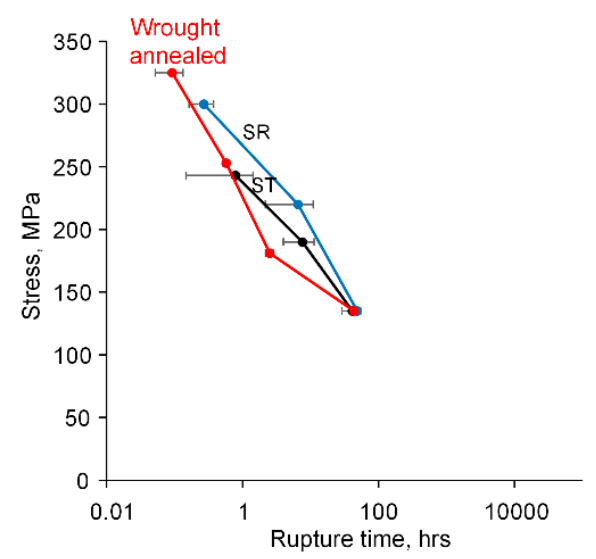

Figure 11. Applied stress versus creep rupture time at $760{ }^{\circ} \mathrm{C}$ for the SR, ST, and wrought annealed IN625 alloys.
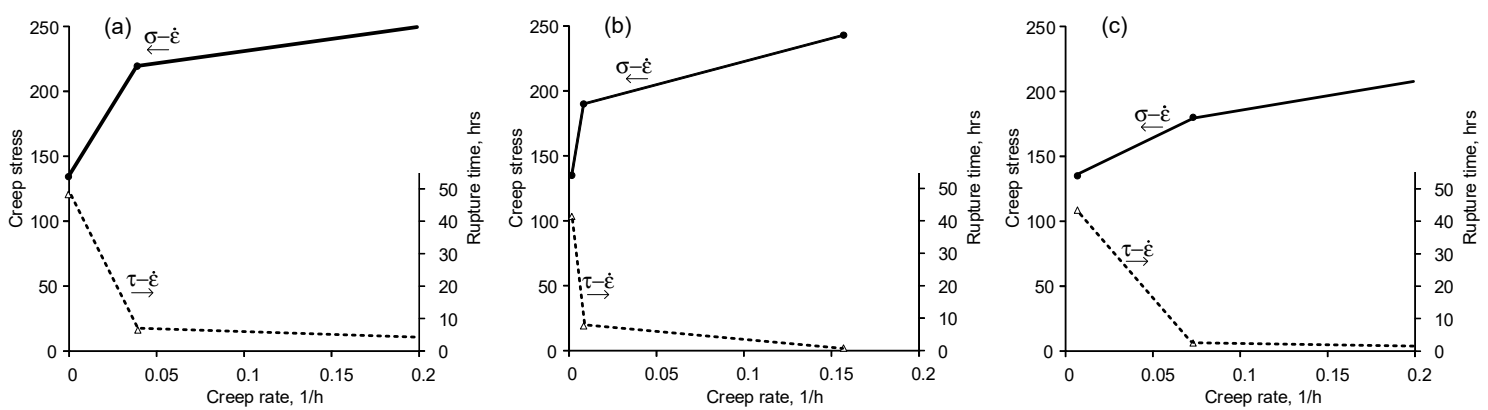

Figure 12. Creep stresses $(\sigma)$ and mean rupture times $(\tau)$ vs. mean steady creep rates $(\dot{\varepsilon})$ for the $(\mathbf{a})$ SR, (b) ST, and (c) wrought annealed IN625 alloys.

In general, creep behavior depends strongly on the metallurgical structure, i.e., the grain and particle sizes, the concentration of the alloying elements, and the creep conditions: stress and temperature. All the structure characteristics mentioned will affect the structural stability against vacancies and dislocations mobility, grain boundary diffusion, and, consequently, crack initiation and propagation at high temperatures under creep stresses [41]. In this study, for example, concentrations of Fe and C in the LPBF alloy were lower than in the wrought alloy. Note that according to the data of Heubner [42], elevated contents of Fe and C in IN625 negatively affect the creep behavior, especially at high temperatures.

Ni-based superalloys are polycrystalline and multiphase materials, and as such, correlating their properties with structural features is not straightforward. In particular, regarding the grain size influence, some data for IN718 demonstrate that an increase in grain size reduced the total creep rupture time, regardless of whether their grain boundaries are clean or intensively decorated with $\delta$ precipitates $(67 \%)$ [43]. However, in classic cases, the trend is just the opposite: the coarser the structure, the greater the creep resistance [41]. A possible explanation for these discrepancies is probably related to the testing methodology: the same stress would create more severe creep conditions for coarse-grained structures with lower strength characteristics (YS, UTS) than for fine-grained structures with higher strength characteristics.

It has also been shown that the greater the density of $\delta$ precipitates at IN718 alloy grain boundaries, the shorter the total creep time, but when this density exceeds $45 \%$, the creep time increases rapidly [43]. It has been suggested that with an increase in the density of precipitates at grain boundaries, the formation of wedge cracks at triple points can be delayed to the stage where creep voids around precipitates situated far from the triple edges are able to grow into unstable cracks. Thus, the beginning of the tertiary stage, characterized by rapid crack propagation, is delayed. Note, however, that in this 
study, all the creep tests were carried out at the same stresses, and thus, the variations in the mechanical strength of alloys with different precipitation densities were not taken into account.

A correlation between the creep rate (Figure 7) and the fractography (Figure 9) observations was be noted. For example, the specimens of the wrought annealed alloy accumulated a significant elongation to failure during their final (tertiary) creep stage, which was reflected by a dimpled fracture surface. At the same time, the ST specimens manifested a long, steady creep stage related to grain boundary sliding, void formation, and crack initiation, which was reflected by fast intergranular/transgranular crack propagation to failure.

Since the aim of the present article was mainly to present the tensile and creep properties of LPBF IN625 alloy, the authors will concentrate more efforts on establishing a correlation between the structural features and the functional properties in the next publication. However, to summarize, the SR-treated IN625 alloy contained needle-like $\delta$ phase and globular precipitates of $\mathrm{M}_{6} \mathrm{C}$ carbides on grain boundaries [24], whereas the grain structures and phase states of the ST- and HIP-treated alloys were comparable. It has been previously shown that HIP dissolves the $\delta$ phase precipitates, forms MC, and homogenizes initially anisotropic SR-structure [24]. Thus, the presence of a significant quantity (that should be evaluated) of intergranular $\delta$ phase precipitates in vertical SR specimens reinforces grain boundaries against the sliding and formation of voids under stresses. After ST, in the case of an equiaxed grain structure with inter- and transgranular carbides, the creep lifetime is less significant, but the ST structure still has advantages over the wrought annealed specimen.

Summary. It was seen that the SR-treated LPBF alloy exhibited the highest anisotropy, i.e., build orientation dependency, and the least predictable mechanical behavior, as compared to its STand HIP-treated counterparts. Therefore, the SR alloy is the least safe material for practical use, especially at elevated temperatures. The ST and HIP treatments improved the alloy homogeneity and provided isotropic properties, thus making these alloys more application-safe. The mechanical strength characteristics of the LPBF alloy after the ST and HIP treatments satisfied the ASTM B444 standard requiring high strength in the $25-593{ }^{\circ} \mathrm{C}\left(68-1100{ }^{\circ} \mathrm{F}\right)$ temperature range.

Note that while the HIP alloy can be seen as a material with more uniform mechanical characteristics and improved ductility over the ST-treated alloy, this advantage came at the expense of the lower strength characteristics.

Furthermore, at $\mathrm{T} \geq 650{ }^{\circ} \mathrm{C}$, special attention must be paid to the time-dependent properties (creep). It was seen that although the LPBF alloy manifested much lower static ductility at these temperatures, it offered significantly longer rupture times under stresses of $<200 \mathrm{MPa}$, as compared to its wrought annealed counterpart (Figure 13).

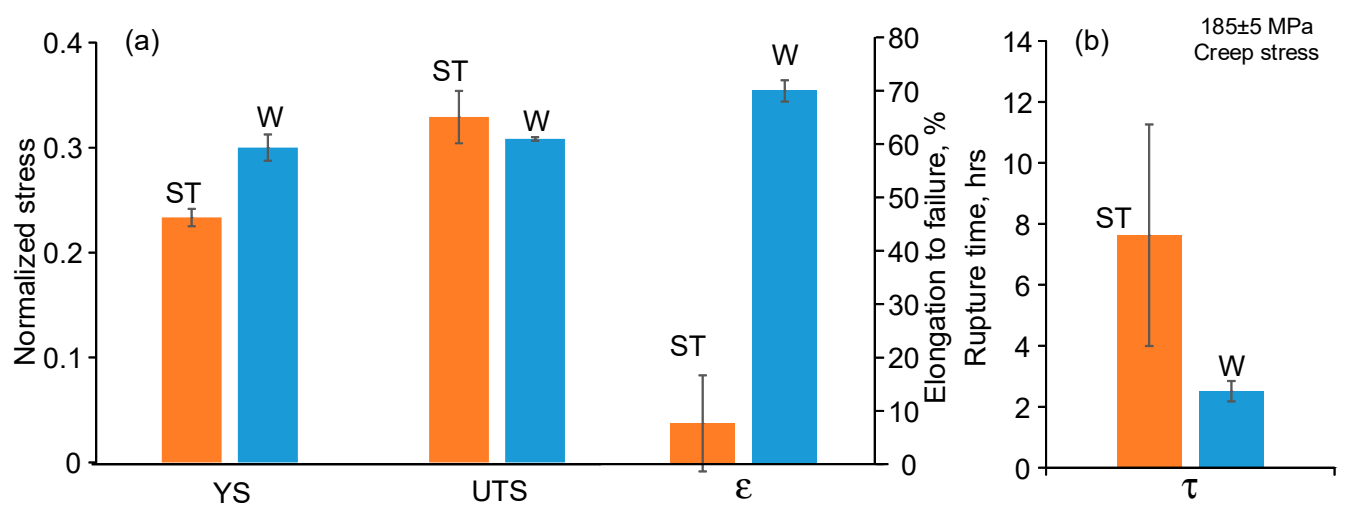

Figure 13. Comparison of the high temperature mechanical properties $\left(760^{\circ} \mathrm{C}, 1400^{\circ} \mathrm{F}\right)$ of the ST LPBF and wrought annealed IN625 alloys: (a) strength (YS, UTS) and elongation to failure $(\varepsilon)$, and (b) creep rupture time $(\tau)$ under a creep stress of $185 \pm 5 \mathrm{MPa}$. 


\section{Conclusions}

1. After SR annealing, the microstructure of LPBF IN625 alloy is anisotropic, characterized by elongated grains mainly oriented along the build direction. ST and HIP treatments lead to the formation of a uniform microstructure.

2. SR annealing provides anisotropic mechanical properties and low elongations, and the highest tensile strength in the $25-593^{\circ} \mathrm{C}$ temperature range. The ST and HIP treatments improved ductility, but this improvement was obtained at the expense of lower mechanical strength characteristics.

3. At elevated temperatures $\left(649-871^{\circ} \mathrm{C}\right)$, the LPBF specimens exhibited low ductility as compared to the wrought annealed alloy. This decrease in ductility was accompanied by a transition from transgranular to intergranular cracking mode.

4. The ST-annealed LPBF alloy exhibited significantly improved creep properties at $760{ }^{\circ} \mathrm{C}$ as compared to the wrought annealed alloy, especially at intermediate and low stresses $(\leq 200 \mathrm{MPa})$.

Author Contributions: The work plan was developed by A.K. and K.I to meet the study objectives defined by V.B and S.T.; Specimens' design, testing and data analysis were performed by A.K. and K.I.; Original draft was prepared by A.K. and K.I; V.B. and S.T. contributed to results interpretation, manuscript review and editing.

Funding: This research was founded by NSERC (Natural Sciences and Engineering Research Council of Canada), CRIAQ (Consortium de Recherche et d'Innovation en Aérospatiale du Québec), Pratt \& Whitney Canada, Fusia, Thermetco and FZ Engineering (Project MANU 1625).

Conflicts of Interest: The authors declare no conflict of interest.

\section{References}

1. Eiselstein, H.L.; Tillack, D.J. The Invention and Definition of Alloy 625, Superalloys 718, 625 and Various Derivatives; Loria, E.A., Ed.; TMS: Pittsburgh, PA, USA, 1991; pp. 1-14.

2. Shankar, V.; Valsan, M.; Rao, K.B.S.; Mannan, S.L. Effects of temperature and strain rate on tensile properties and activation energy for dynamic strain aging in alloy 625. Met. Mater. Trans. A 2004, 35, 3129-3139. [CrossRef]

3. Liu, D.; Zhang, X.; Qin, X.; Ding, Y. High-temperature mechanical properties of Inconel-625: Role of carbides and delta phase. Mater. Sci. Technol. 2017, 33, 1610-1617. [CrossRef]

4. MIL-HDBK-5H: Metallic Materials and Elements for Aerospace Vehicle Structures; Military Handbook; U.S. Department of Defense: Washington, DC, USA, 1998.

5. Deel, O. Mechanical Property Data Inconel 625; Battelle Memorial Institute, Defense Technical Information Center: Columbus, OH, USA, 1971.

6. Kohler, M. Effect of the Elevated-Temperature-Precipitation in Alloy 625 on Properties and Microstructure, Superalloys 718, 625 and Various Derivatives; Loria, E.A., Ed.; The Minerals, Metals and Materials Society: Pittsburgh, PA, USA, 1991; pp. 363-374.

7. Debroy, T.; Wei, H.; Zuback, J.; Mukherjee, T.; Elmer, J.; Milewski, J.; Beese, A.; Wilson-Heid, A.; De, A.; Zhang, W. Additive manufacturing of metallic components-Process, structure and properties. Prog. Mater. Sci. 2018, 92, 112-224. [CrossRef]

8. Herzog, D.; Seyda, V.; Wycisk, E.; Emmelmann, C. Additive manufacturing of metals. Acta Mater. 2016, 117, 371-392. [CrossRef]

9. Bhavar, V.; Kattire, P.; Patil, V.; Khot, S.; Gujar, K.; Singh, R. A review on powder bed fusion technology of metal additive manufacturing. In Proceedings of the 4th International Conference and Exhibition on Additive Manufacturing Technologies-AM-2014, Banglore, India, 1-2 September 2014; pp. 1-2.

10. Donachie, M.J.; Donachie, S.J. Superalloys a Technical Guide, 2nd ed.; ASM International: Materials Park, OH, USA, 2002.

11. Amato, K.; Gaytan, S.; Murr, L.; Martinez, E.; Shindo, P.; Hernandez, J.; Collins, S.; Medina, F.; Murr, L. Microstructures and mechanical behavior of Inconel 718 fabricated by selective laser melting. Acta Mater. 2012, 60, 2229-2239. [CrossRef]

12. Li, C.; White, R.; Fang, X.; Weaver, M.; Guo, Y. Microstructure evolution characteristics of Inconel 625 alloy from selective laser melting to heat treatment. Mater. Sci. Eng. A 2017, 705, 20-31. [CrossRef] 
13. Amato, K.N.; Hernandez, J.; Murr, L.E.; Martinez, E.; Gaytan, S.M.; Shindo, P.W.; Collins, S. Comparison of Microstructures and Properties for a Ni-Base Superalloy (Alloy 625) Fabricated by Electron and Laser Beam Melting. J. Mater. Sci. Res. 2012, 1, 3-41.

14. Li, Y.; Gu, D. Parametric analysis of thermal behavior during selective laser melting additive manufacturing of aluminum alloy powder. Mater. Des. 2014, 63, 856-867. [CrossRef]

15. Shiomi, M.; Osakada, K.; Nakamura, K.; Yamashita, T.; Abe, F. Residual Stress within Metallic Model Made by Selective Laser Melting Process. CIRP Ann. 2004, 53, 195-198. [CrossRef]

16. Kreitcberg, A.; Brailovski, V.; Turenne, S. Effect of heat treatment and hot isostatic pressing on the microstructure and mechanical properties of Inconel 625 alloy processed by laser powder bed fusion. Mater. Sci. Eng. A 2017, 689, 1-10. [CrossRef]

17. Mostafa, A.; Rubio, I.P.; Brailovski, V.; Jahazi, M.; Medraj, M. Structure, Texture and Phases in 3D Printed IN718 Alloy Subjected to Homogenization and HIP Treatments. Metals 2017, 7, 196. [CrossRef]

18. Ferrer, L.; Pieraggi, B.; Uginet, J.F. Microstructure Evolution during Thermomechanical Processing of Alloy 625, Superalloys 718, 625 and Various Derivatives; Loria, E.A., Ed.; The Minerals, Metals and Materials Society: Pittsburgh, PA, USA, 1991; pp. 217-228.

19. Brown, C.U.; Jacob, G.; Stoudt, M.; Moylan, S.; Slotwinski, J.; Donmez, A. Interlaboratory study for nickel alloy 625 made by laser powder bed fusion to quantify mechanical property variability. J. Mater. Eng. Perform. 2016, 25, 3390-3397. [CrossRef] [PubMed]

20. Hack, H.; Link, R.; Knudsen, E.; Baker, B.; Olig, S. Mechanical properties of additive manufactured nickel alloy 625. Addit. Manuf. 2017, 14, 105-115. [CrossRef]

21. Marchese, G.; Lorusso, M.; Parizia, S.; Bassini, E.; Lee, J.-W.; Calignano, F.; Manfredi, D.; Terner, M.; Hong, H.-U.; Ugues, D.; et al. Influence of heat treatments on microstructure evolution and mechanical properties of Inconel 625 processed by laser powder bed fusion. Mater. Sci. Eng. A 2018, 729, 64-75. [CrossRef]

22. Zheng, L.; Schmitz, G.; Meng, Y.; Chellali, R.; Schlesiger, R. Mechanism of Intermediate Temperature Embrittlement of Ni and Ni-based Superalloys. Crit. Rev. Solid State Mater. Sci. 2012, 37, 181-214. [CrossRef]

23. Murr, L.E.; Martinez, E.; Gaytan, S.M.; Ramirez, D.A.; Machado, B.I.; Shindo, P.W.; Martinez, J.L.; Medina, F.; Wooten, J.; Ciscel, D.; et al. Microstructural Architecture, Microstructures, and Mechanical Properties for a Nickel-Base Superalloy Fabricated by Electron Beam Melting. Met. Mater. Trans. A 2011, 42, 3491-3508. [CrossRef]

24. Kreitcberg, A.; Brailovski, V.; Turenne, S. Elevated temperature mechanical behavior of IN625 alloy processed by laser powder-bed fusion. Mater. Sci. Eng. A 2017, 700, 540-553. [CrossRef]

25. Davis, J.R. ASM Specialty Handbook: Nickel, Cobalt, and Their Alloys; ASM International: Geauga County, $\mathrm{OH}$, USA, 2000; p. 442.

26. Kuo, Y.-L.; Horikawa, S.; Kakehi, K. Effects of build direction and heat treatment on creep properties of Ni-base superalloy built up by additive manufacturing. Scr. Mater. 2017, 129, 74-78. [CrossRef]

27. Kuo, Y.-L.; Nagahari, T.; Kakehi, K. The Effect of Post-Processes on the Microstructure and Creep Properties of Alloy718 Built Up by Selective Laser Melting. Materials 2018, 11, 996. [CrossRef]

28. Xu, Z.; Murray, J.W.; Hyde, C.J.; Clare, A.T. Effect of post processing on the creep performance of laser powder bed fused Inconel 718. Addit. Manuf. 2018, 24, 486-497. [CrossRef]

29. Xu, Z.; Hyde, C.J.; Tuck, C.; Clare, A.T. Creep behavior of Inconel 718 processed by laser powder bed fusion. J. Mater. Process. Technol. 2018, 256, 13-24. [CrossRef]

30. Pröbstle, M.; Neumeier, S.; Hopfenmüller, J.; Freund, L.P.; Niendorf, T.; Schwarze, D.; Göken, M. Superior creep strength of a nickel-based superalloy produced by selective laser melting. Mater. Sci. Eng. A 2016, 674, 299-307. [CrossRef]

31. Chang, S.-H.; Lee, S.-C.; Tang, T.-P.; Ho, H.-H. Influences of Soaking Time in Hot Isostatic Pressing on Strength of Inconel 718 Superalloy. Mater. Trans. 2006, 47, 426-432. [CrossRef]

32. "Special Metals", Inconel Alloy 625. Available online: www.specialmetals.com/assets/smc/documents/alloys/ inconel/inconel-alloy-625.pdf (accessed on 31 May 2019).

33. "Special Metals", Inconel Alloy 625. Available online: https://www.haraldpihl.com/globalassets/pdf/033 inconel-alloy-625lcf.pdf (accessed on 31 May 2019).

34. Das, S.; Wohlert, M.; Beaman, J.J.; Bourell, D.L. Direct Selective Laser Sintering of high performance metals for containerless HIP. Adv. Powder Metall. Part. Mater. 1997, 3, 81-90. 
35. Carlson, R.G. Cast 625 Hot Isostatic Pressing (HIP) Parameters-A Statistically Designed Study, Superalloys 718, 625 and Various Derivatives; Loria, E.A., Ed.; The Minerals, Metals and Materials Society: Pittsburgh, PA, USA, 1991; pp. 97-106.

36. ASTM. Standard Specification for Additive Manufacturing Nickel Alloy (UNS N06625) with Powder Bed Fusion; ASTM International: West Conshohocken, PA, USA, 2014.

37. Kohler, M.; Heubner, U. The Effect of Final Heat Treatment and Chemical Composition on Sensitization, Strength and Thermal Stability of Alloy 625. Superalloys 718,625,706 and Various Derivatives; Loria, E.A., Ed.; The Minerals, Metals \& Materials Society: Pittsburgh, PA, USA, 1997; pp. 795-803.

38. Yadroitsev, I.; Thivillon, L.; Bertrand, P.; Smurov, I.; Bertrand, P. Strategy of manufacturing components with designed internal structure by selective laser melting of metallic powder. Appl. Surf. Sci. 2007, 254, 980-983. [CrossRef]

39. Vernot-Loier, C.; Cortial, F. Influence of Heat Treatments on Microstructure, Mechanical Properties and Corrosion Behavior of Alloy 625 Forged Rod, Superalloys 718, 625 and Various Derivatives; Loria, E.A., Ed.; The Minerals, Metals and Materials Society: Pittsburgh, PA, USA, 1991; p. 409.

40. Cortial, F.; Corrieu, J.M.; Vernot-Loier, C. Heat Treatments of Weld Alloy 625: Influence on the Microstructure, Mechanical Properties and Corrosion Resistance, Superalloys 718, 625, 706 and Various Derivatives; Loria, E.A., Ed.; The Minerals, Metals and Materials Society: Pittsburgh, PA, USA, 1994; p. 859.

41. Reed, R.C. The Superalloys: Fundamentals and Applications; Cambridge University Press: New York, NY, USA, 2006.

42. Heubner, U.; Kohler, M. Effect of Carbon Content and Other Variables on Yield Strength, Ductility and Creep Properties of Alloy 625, Superalloys 718,625,706 and Various Derivatives; Loria, E.A., Ed.; The Minerals, Metals \& Materials Society: Pittsburgh, PA, USA, 1994; pp. 479-488.

43. Chen, W.; Chaturvedi, M. Dependence of creep fracture of inconel 718 on grain boundary precipitates. Acta Mater. 1997, 45, 2735-2746. [CrossRef]

(C) 2019 by the authors. Licensee MDPI, Basel, Switzerland. This article is an open access article distributed under the terms and conditions of the Creative Commons Attribution (CC BY) license (http://creativecommons.org/licenses/by/4.0/). 